\title{
Annual cost of hospitalization, inpatient rehabilitation, and sick leave for head and neck cancers in Germany
}

This article was published in the following Dove Press journal:

ClinicoEconomics and Outcomes Research

15 May 2013

Number of times this article has been viewed

\author{
Jens P Klussmann' \\ Peter K Schädlich² \\ Xiaoyu Chen ${ }^{2}$ \\ Vanessa Rémy ${ }^{3}$
}

'Department of Otorhinolaryngology, Head and Neck Surgery, University of Giessen, Giessen, ${ }^{2}$ GES Institut, Berlin, Germany; ${ }^{3}$ Sanofi Pasteur MSD, Lyon, France
Correspondence: Xiaoyu Chen IGES Institut $\mathrm{GmbH}$, Friedrichstr 180 , I0II 7 Berlin, Germany Tel +49302308090 Fax +4930230809 II Email xiaoyu.chen@iges.de
Background: Data on the economic burden of head and neck cancers (HNCs) in Germany is scarce. About $16 \%-28 \%$ of these cancers are associated with human papillomavirus (HPV) infection. Therefore, the study reported here aimed to assess the annual costs of HPV-related HNCs incurred by hospitalization, inpatient rehabilitation, and sick leave in Germany in 2008.

Methods: A cross-sectional retrospective analysis of five German databases covering hospital treatment, inpatient rehabilitation, and sick leave in 2008 was performed. All hospital, inpatient rehabilitation, and sick leave cases due to HNCs in 2008 were analyzed. Associated numbers of HNC hospitalizations, health care resource use, and costs were identified and extracted using the International Classification of Diseases, tenth revision (ICD-10; World Health Organization, Geneva, 1990) codes C01-C06, C09-C14, and C32 as the main diagnoses. Resources were valued with German official prices in 2008 euros $(€)$. The annual costs of HPV-related HNCs were estimated based on the percentage of HNCs likely to be attributable to HPV infection.

Results: In 2008, there were 63,857 hospitalizations, 4898 inpatient rehabilitations, and 17,494 sick leaves due to HNCs, representing costs of $€ 365.78$ million. The estimated annual costs associated with HPV-related HNCs were $€ 78.22$ million, mainly attributed to males (80\%). Direct costs accounted for $84 \%$ (80\% for hospital treatment, $4 \%$ for inpatient rehabilitation) and indirect costs due to sick leave accounted for $16 \%$ of HPV-related HNC costs.

Conclusion: The economic burden of HPV-related HNCs in Germany in 2008 has been underestimated, since costs incurred by outpatient management, outpatient chemotherapy, long-term care, premature retirement, and premature death were not included. However, as far as we are aware, this study is the first analysis to investigate the economic burden of HNCs in Germany. The estimated annual costs of HPV-related HNCs contribute to a significant economic burden in Germany and should be considered when assessing the health and economic benefits of HPV vaccination in both sexes.

Keywords: human papillomavirus, cost of illness, HPV, economic burden, 2008

\section{Introduction}

Head and neck cancers (HNCs) comprise a broad spectrum of cancers in various anatomical sites, including the lips, oral cavity, oropharynx, pharynx, and larynx. ${ }^{1-3}$ The incidence and mortality rates of these cancers vary worldwide and are generally higher in developing countries. ${ }^{2,4}$ The highest incidence of these cancers is observed in males and in those older than 50 years. ${ }^{2,3}$ In 2008, HNCs accounted for 133,664 new cancers and were responsible for more than 63,000 deaths in Europe. ${ }^{5}$

In Germany in 2008, there were 9520 new cancers of the oral cavity and pharynx (International Classification of Diseases, tenth revision [ICD-10] ${ }^{6}$ codes C00-C14) in males and 3490 in females, and 3610 new cancers of the larynx (ICD-10 C32) in 
males and 510 in females. ${ }^{7}$ Oral cavity and pharynx cancers represented the fifth most common cancers in males (3.9\%) and the fifteenth most common in females (1.6\%); while larynx cancer was the sixteenth most common cancer in males $(1.5 \%)$ and the twenty-second most common in females $(0.2 \%))^{7}$ The standardized incidence rate (Europe) per 100,000 was 19.1 in males and 5.9 in females for oral cavity and pharynx cancers, and 6.9 in males and 0.9 in females for larynx cancer. ${ }^{7}$ There were 3776 deaths due to oral cavity and pharynx cancers in males and 1170 in females, as well as 1275 deaths due to larynx cancer in males and 209 in females; the standardized mortality rate (Europe) per 100,000 was 7.4 in males and 1.8 in females for oral cavity and pharynx cancers, and 2.4 in males and 0.3 in females for larynx cancer. ${ }^{7}$

The well-known major risk factors for HNCs include tobacco smoking and alcohol consumption, which act synergistically. Poor oral hygiene is also regarded as a possible risk factor for oral cavity cancer. ${ }^{1,7}$ In addition, numerous studies have shown the increasing role of sexually transmitted human papillomavirus (HPV) infection in the incidence of HNCs. ${ }^{1,2,4,8,9}$ The HPV-associated proportions vary greatly according to the anatomic site of the $\mathrm{HNC}$; examples include oral cavity cancer $\left(16 \%{ }^{9}\right.$ and $\left.23.5 \%{ }^{2}\right)$, oropharynx cancer $\left(28.2 \%{ }^{9}\right.$ up to $\left.72.0 \%{ }^{2}\right)$, pharynx other $\left(21.3 \%{ }^{9}\right.$ and $\left.24.0 \%^{2}\right)$, other sites in the lip, oral cavity and pharynx areas (28.2\% ${ }^{9}$ up to $72.0 \%^{2}$ ), or larynx cancer (average $21.3 \%$, range 5.0\%-24.0\%). ${ }^{9}$ The wide variations in reported HPV prevalence may depend on the HPV diagnostic methodology, especially in earlier studies.

The precursor lesion of HNCs is squamous intraepithelial neoplasia (SIN), which is graded from 1 (mild) to 3 (severe, carcinoma in situ).${ }^{10}$ The prevalence and incidence of SIN in Germany as a whole are unknown. ${ }^{10}$ In the region of Thuringia in Germany, the average annual crude incidence of SIN 3 (HNC in situ) was 0.14 per 100,000 persons during 1996-2005. ${ }^{9}$

Treatment of HNCs focuses on surgery, radiotherapy, chemotherapy, or a combination of these (so-called multimodal therapy). ${ }^{2,11,12}$ Early stage disease is treated by one modality, whereas multimodal therapy is frequently applied in advanced disease states. ${ }^{2,11,12}$ However, the overall prognosis remains poor. According to an analysis of the regional Thuringian cancer registration database in Germany, there was no significant improvement of the 5-year overall survival rate of HNCs from 1996 to 2005, though treatment strategies have changed to more frequently applied multimodal therapy. ${ }^{11}$
A number of studies assessing the disease burden and cost

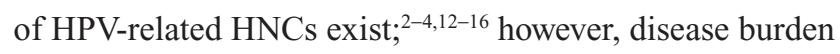
and cost are poorly documented in Germany because, as far as we are aware, no studies of the German setting exist. Therefore, the objective of the study reported here was to estimate the economic burden due to hospitalization, inpatient rehabilitation, and sick leave of HPV-related HNCs in Germany in 2008.

\section{Materials and methods Study design}

The study was based on a retrospective cross-sectional analysis of five German databases that cover hospitalizations, ${ }^{17}$ distribution of diagnosis-related groups (DRGs) and major categories of treatment during hospital stay, ${ }^{18}$ inpatient rehabilitation, ${ }^{19}$ and sick leave, ${ }^{20,21}$ each with the reference year 2008. These databases are described in detail following.

Associated numbers of $\mathrm{HNC}$ hospitalizations, health care resource use, and unit costs were identified and extracted using the ICD-10 codes C01-C06, C09-C14, and C32 as the main diagnoses, henceforth called "cancers of interest." Depending on the different anatomic sites, these diseases were classed within five cancer categories: (1) oral cavity (C02-C06: tongue other, gum, floor of mouth, palate, mouth other), (2) oropharynx (C01, C09-C10: base of tongue, tonsil, oropharynx), (3) pharynx other (C11-C13: nasopharynx, piriform sinus, hypopharynx), (4) other sites (C14: other/ ill-defined sites in the lip, oral cavity and pharynx), and (5) larynx (C32: larynx). The extracted numbers of cases refer to resource consumption units and not to patients. Annual costs of HPV-related HNCs were estimated by considering the cancer-specific proportions attributable to HPV infection (not sex-specific). ${ }^{2,9}$

The annual cost of HNCs was estimated by considering the expenditure of social insurance bodies as proxies for direct medical costs incurred by hospital treatment and inpatient rehabilitation. Indirect costs due to sick leave were estimated using the human capital approach, which measures productivity losses by multiplying the work time lost as a consequence of illness by the gross earnings of the individuals affected. Resources were valued with German official prices in 2008 euros $(€)$.

Outpatient management and patients' co-payments and out-of-pocket expenses were not considered. Further information on which components were and were not included in the study is presented in Table 1. 
Table I Cost components of the analysis

\begin{tabular}{|c|c|c|}
\hline Cost component & $\begin{array}{l}\text { Included } \\
\text { in the analysis }\end{array}$ & $\begin{array}{l}\text { Not included } \\
\text { in the analysis }\end{array}$ \\
\hline \multicolumn{3}{|c|}{ Direct costs given by expenditure of social insurance bodies } \\
\hline Hospitalization $^{\mathrm{a}}$ & $\mathrm{x}$ & \\
\hline \multicolumn{3}{|l|}{ during hospitalization ${ }^{\mathrm{b}}$} \\
\hline $\begin{array}{l}\text { covering physician visits, } \\
\text { diagnostics, and treatments }\end{array}$ & & $\mathrm{X}$ \\
\hline \multicolumn{3}{|l|}{ chemotherapy } \\
\hline \multicolumn{2}{|l|}{ employed patients } & \\
\hline \multicolumn{3}{|l|}{ retired patients } \\
\hline Outpatient rehabilitation & & $\mathrm{X}$ \\
\hline Long-term care ${ }^{c}$ & & $x$ \\
\hline \multicolumn{3}{|c|}{ Indirect costs based on the human capital approach } \\
\hline Sick leave & $\mathrm{x}$ & \\
\hline Premature retirement & & $\mathrm{x}$ \\
\hline Premature death & & $\mathrm{x}$ \\
\hline \multicolumn{3}{|c|}{$\begin{array}{l}\text { Notes: alncluding inter alia inexpensive chemotherapy covered and reimbursed by } \\
\text { respective diagnosis-related groups; }{ }^{b} \text { no expensive chemotherapy that is reimbursed } \\
\text { via an additional fee could be linked to the extracted diagnosis-related groups due } \\
\text { to the nature of the database used (G-DRG Browser }{ }^{18} \text {; ; variety of services provided } \\
\text { in institutional or home care settings for those who are unable to perform activities } \\
\text { of daily living independently for an expected period of at least half a year due to } \\
\text { illness or disability. }\end{array}$} \\
\hline
\end{tabular}

\section{Estimation of direct costs incurred by hospitalization}

The annual cost incurred by hospital treatment (medical attendance, care, drugs, devices, physical therapy, board and lodging) of HNCs was based on the number of hospitalizations and the average cost per hospital stay. The number of hospital stays with a main diagnosis of the cancers of interest was extracted from the hospital statistics published by the Federal Statistical Office Germany (Destatis). ${ }^{17}$ These statistics are by law exhaustive for all Germany ${ }^{17}$ and provide information on the number of hospitalizations by ICD-10 code, age group, and sex. ${ }^{17}$

The average hospital treatment cost per hospitalization for HNCs was derived from the type and number of German diagnosis-related group (G-DRG) positions reimbursed for a main diagnosis of the cancers of interest. G-DRG data are by law exhaustive for all Germany ${ }^{18}$ and are published by the Institute for the Hospital Remuneration System as "G-DRG Browser," 18 which provides information on type and frequency of reimbursed G-DRGs per ICD-10 main diagnosis as well as type and frequency of major treatment categories such as surgery, radiotherapy, and medical treatment per reimbursed G-DRG position.
Costs for each extracted G-DRG position related to a main diagnosis of the cancers of interest were calculated multiplying the cost weight of each extracted G-DRG position ${ }^{18}$ with the Germany-wide average base rate of $€ 2803.05$ in $2008 .{ }^{22,23}$ The cost weight is a DRG-specific factor that depends on diagnosis, secondary diagnosis, age, whether or not surgery is conducted, type of surgical procedures, and complications. The cost weight thus reflects the intensity of resource consumption during hospital stay relative to the average case value, which is represented by the base rate in monetary terms.

For all G-DRG positions, the G-DRG Browser only lists the top-20 main diagnoses. If a case has a main diagnosis that is among the top 20 of a certain DRG, this case shows up in the browser data. If a rare main diagnosis uses a G-DRG that is used by many other more frequent main diagnoses, it will not show up in the browser. The extrapolation of costs from the number of cases in the G-DRG Browser to the number of cases from the hospital statistics was done directly for cancers of interest with less than $30 \%$ of missing cases compared with the hospital statistics. In the case of cancers of interest with more than $30 \%$ of missing cases compared with the hospital statistics, the extrapolation was supplemented by collection of aggregate anonymized data on the distribution of G-DRG positions for treatment of these cancers of interest in one hospital to identify potential important missing G-DRGs.

Hospital treatment costs extrapolated from the G-DRG Browser $^{18}$ data were stratified by sex assuming the same distribution for costs as for the number of hospitalizations extracted from the hospital statistics. ${ }^{17}$

\section{Estimation of direct costs incurred by inpatient rehabilitation}

For HNC patients, rehabilitation care includes nutritional counseling, therapy for dysphagia, psychosocial training to accept a changed appearance, training in the use of prosthesis, restoration of oral communication ability, and manual lymphatic drainage. The annual cost incurred by inpatient rehabilitation due to the cancers of interest after acute hospital cancer treatment was based on the number and average duration of rehabilitation stay (in days) and the average cost per day.

The number of rehabilitation stays with a main diagnosis of the cancers of interest was extracted from the rehabilitation statistics published by the holder of the German Public Pension Insurance (DRV) ${ }^{19}$ These statistics are by law exhaustive 
for all Germany ${ }^{19}$ and provide information on the number of inpatient rehabilitation stays and duration in days by ICD-10 three-digit code and sex. ${ }^{19}$ Outpatient rehabilitation was not included in this study, as the related data are aggregated over disease groups, ${ }^{19}$ thus preventing ICD-10 three-digit codes from being extracted.

The average cost per day of inpatient rehabilitation was also derived from rehabilitation statistics. ${ }^{19}$ Total costs of $€ 2,689.84$ million $^{19}$ divided by a total of $24,120,180$ days $(804,006 \text { cases with a mean of } 30 \text { days per stay })^{19}$ resulted in an average cost of $€ 111.52$ per day for inpatient rehabilitation. This average cost per day is not disease-specific.

The number, length of stay, and cost of inpatient rehabilitation stays were stratified by sex.

\section{Estimation of indirect costs incurred by sick leave}

The annual cost incurred by sick leave due to the cancers of interest was based on the number of sick leaves, the average duration per case in days, and cost per day.

The number and duration of sick leaves were estimated in two steps. In the first step, the number of sick leave cases and average duration per sick leave case in days due to the cancers of interest, each by sex, were extracted from statistics covering the population of all compulsory members (ie, insured without co-insured dependants and pensioners) of the Local Statutory Health Insurance (SHI) fund (AOK), which is the biggest of the SHI funds in Germany. These statistics are available via the Information System of Federal Health Monitoring (GBE) ${ }^{20}$ As these data are not exhaustive for all Germany, a second step was applied to extrapolate the numbers and duration of sick leave cases by sex extracted from the AOK statistics ${ }^{20}$ to the total German compulsory SHI member population, based on statistics of the total German SHI population published by the Federal Ministry of Health (Bundesministerium für Gesundheit), the KM6 statistics. ${ }^{21}$ This was done based on the sex-specific share compulsory AOK members took in the total compulsory SHI member population in 2008, available from the KM6 statistics. ${ }^{21}$

Using the human capital approach, ${ }^{24}$ the overall employee compensation per employee per day was used as cost per day of sick leave. The overall employee compensation per employee per day in 2008 was derived from the Statistical Yearbook. ${ }^{25}$ An overall employee compensation of $€ 1225.84$ billion $^{25}$ divided by 35,845,000 employees ${ }^{25}$ and 365 days resulted in $€ 93.69$ per employee per day.
The number, duration (in days), and costs incurred by sick leave were stratified by sex.

\section{Estimation of annual costs of HNCs and of HPV-related HNCs}

The annual cost of HNCs was estimated by adding costs incurred by hospitalization, inpatient rehabilitation, and sick leave. These annual costs were stratified by direct and indirect costs as well as by sex.

A separate calculation was made to estimate the total annual cost of HPV-related HNCs, considering the cancerspecific proportions attributable to HPV infection ${ }^{2,9}$ (Table 2). This was also stratified by direct and indirect costs as well as by sex.

\section{Statistical methods}

Due to the nature of the databases used, ${ }^{17-20}$ which exclusively provide average values of all the cases comprised, no measure of variability could be quoted for the estimated cost figures for HNCs. However, this is deemed acceptable, as the hospital and rehabilitation statististics ${ }^{17,19}$ are by law exhaustive for all Germany. ${ }^{17,19}$ In addition, the G-DRG-related base rate $^{22,23}$ to estimate costs incurred by hospitalization and the cost per day of inpatient rehabilitation ${ }^{19}$ to estimate costs incurred by inpatient rehabilitation each are Germany-wide averages. ${ }^{19,22,23}$ Hence, the use of Germany-wide averages and the fact that the data are exhaustive allowed us to refrain from sensitivity analysis, as no variability was expected.

However, for the estimation of HPV-related costs, the average values and limits of the cancer-specific proportions attributable to HPV infection (Table 2) were applied to receive a range of these costs. When no explicit lower limit was reported, the available average value was used as a substitute for the respective lower limit (Table 2) to avoid speculative assumptions. All analyses were performed using Microsoft ${ }^{\circledR}$ Excel 2007 (Microsoft, Redmond, WA, USA).

Table 2 Average and limits of head and neck cancer-specific proportions attributable to human papillomavirus infection

\begin{tabular}{llll}
\hline $\begin{array}{l}\text { Cancer category } \\
\text { (ICD-I0 code) }\end{array}$ & $\begin{array}{l}\text { Lower } \\
\text { limit, \% }\end{array}$ & Average, \% & $\begin{array}{l}\text { Upper } \\
\text { limit, \% }\end{array}$ \\
\hline Oral cavity (CO2-C06) & $16.0^{9}$ & $16.0^{9}$ & $23.5^{2}$ \\
Oropharynx (COI, C09-CI0) & $28.2^{9}$ & $28.2^{9}$ & $72.0^{2}$ \\
Pharynx other (CII-CI3) & $21.3^{9}$ & $21.3^{9}$ & $24.0^{2}$ \\
Other sites* (CI4) & $28.2^{9}$ & $28.2^{9}$ & $72.0^{2}$ \\
Larynx (C32) & $5.0^{9}$ & $21.3^{9}$ & $24.0^{9}$ \\
\hline
\end{tabular}

Note: *Other/ill-defined sites in the lip, oral cavity, and pharynx.

Abbreviation: ICD-10, International Classification of Diseases, tenth revision. ${ }^{6}$ 


\section{Results}

\section{Direct costs incurred by hospitalization} Number of hospitalizations

In 2008, there were 63,857 hospitalizations for HNCs in Germany: 50,869 for males (80\%) and 12,988 for females $(20 \%)$. The number of hospitalizations by cancer category and sex is given in Table 3 . The most frequent was oropharynx cancer $(29 \%)$, followed by cancer of the oral cavity (26\%), larynx (25\%), pharynx other (19\%), and other sites (1\%). The distribution of the number of hospitalizations by age group and cancer category is given in Figure 1. The number of hospitalizations increased starting from age 35-39 years. Hospitalizations for oropharynx and pharynx other cancers peaked in the 55-59 year age group, whereas all remaining $\mathrm{HNC}$ hospitalizations peaked in the 65-69 year age group (Figure 1). Considering all HNCs together, the number of hospitalizations showed a bimodal age distribution; hospitalizations were most frequent in the $55-59$ year age group $(n=11,355)$, followed closely by the 65-69 year age group $(n=11,276)$. Of all hospitalizations due to HNCs, $78 \%$ were for patients between 40 and 69 years of age; $53 \%$ and $38 \%$ were for patients older than 60 and 65 years, respectively.

\section{Major categories of treatment}

The distribution of the hospitalizations by major treatment categories for each HNC category was derived from the G-DRG codes extracted from the G-DRG Browser. ${ }^{18}$ This distribution is displayed in Figure 2 and shows some variation depending on the cancer category. Considering all HNCs together, most of the hospitalizations (not patients) were linked to surgical procedures exclusively (41\%), followed by medical treatment (37\%) and radiotherapy exclusively (19\%). Combination treatment of surgery and radiotherapy accounted for $2 \%$ of the hospitalizations. All important
G-DRGs for HNC treatment seemed to be accounted for in the G-DRG Browser as the hospital data showed.

\section{Costs}

Compared with the hospital statistics, ${ }^{17}$ more than $30 \%$ of hospitalizations were missing in the G-DRG Browser ${ }^{18}$ for six of the 13 ICD-10 codes related to HNCs: C03 (gum), C05 (palate), C06 (mouth other), C11 (nasopharynx), C12 (piriform sinus), and C14 (other/ill-defined sites in the lip, oral cavity, and pharynx). However, the collected anonymized hospital data for these six ICD-10 codes showed that no important G-DRGs were missed compared with the extracted G-DRG Browser data. Hence, average costs per hospitalization derived from the cost weight of each extracted G-DRG position ${ }^{18}$ and the Germany-wide average base rate ${ }^{22,23}$ were used for the extrapolation of costs from the number of hospitalizations in the G-DRG Browser to the number of hospitalizations from the hospital statistics for all 13 ICD-10 codes for HNCs. In 2008, HNC hospitalizations had a total cost of $€ 293.66$ million in Germany, of which $€ 228.75$ million were attributed to males ( $78 \%$ ) and $€ 64.91$ million to females $(22 \%)$. The distribution of these costs by cancer category and sex is given in Table 4. The main contributors to these costs were oral cavity $(37 \%)$ and oropharynx cancers $(27 \%)$.

\section{Direct costs incurred by inpatient rehabilitation}

In 2008, there were 4898 inpatient rehabilitations for HNCs in Germany - 3798 for males (78\%) and 1100 for females $(22 \%)$ - corresponding to a total of 117,506 days of inpatient rehabilitation for HNCs. The number of inpatient rehabilitations and length of stay by cancer category and sex are given in Table 3. Based on an average cost of $€ 111.52$ per day, the cost incurred by inpatient rehabilitation was $€ 13.10$ million, of which $€ 10.05$ million was attributed to males (77\%) and

Table 3 Resource consumption units by head and neck cancer category and sex in Germany in 2008 (any inconsistencies are due to rounding)

\begin{tabular}{|c|c|c|c|c|c|c|}
\hline \multirow[t]{2}{*}{$\begin{array}{l}\text { Cancer category } \\
\text { (ICD- I } 0 \text { code) }\end{array}$} & \multicolumn{2}{|c|}{$\begin{array}{l}\text { Number of } \\
\text { hospitalizations }\end{array}$} & \multicolumn{2}{|c|}{$\begin{array}{l}\text { Number of inpatient } \\
\text { rehabilitations (LOS in } \\
\text { days per rehabilitation) }\end{array}$} & \multicolumn{2}{|c|}{$\begin{array}{l}\text { Number of sick leaves } \\
\text { (duration in days per sick } \\
\text { leave) }\end{array}$} \\
\hline & Males & Females & Males & Females & Males & Females \\
\hline Oral cavity (C02-C06) & 11,929 & 4965 & $937(24)$ & $45 \mid(25)$ & $3862(4 I)$ & $976(31)$ \\
\hline Oropharynx (C0I, C09-CI0) & 14,396 & 4110 & $1118(24)$ & $378(25)$ & $4339(35)$ & $680(35)$ \\
\hline Pharynx other $(\mathrm{ClI}-\mathrm{Cl} 3)$ & 10,268 & 1908 & 691 (24) & $105(25)$ & $2683(34)$ & $349(48)$ \\
\hline Other sites* $(\mathrm{Cl} 4)$ & 532 & 129 & $62(24)$ & $10(25)$ & $207(49)$ & $52(45)$ \\
\hline Larynx (C32) & 13,744 & 1876 & $990(23)$ & $156(24)$ & $3,754(35)$ & $592(26)$ \\
\hline Total & 50,869 & 12,988 & $3798(23.7)$ & $1100(24.9)$ & $14,846(36.0)$ & $2649(34.0)$ \\
\hline
\end{tabular}

Note: *Other/ill-defined sites in the lip, oral cavity, and pharynx.

Abbreviations: ICD-10, International Classification of Diseases, tenth revision ${ }^{6}$; LOS, length of stay. 


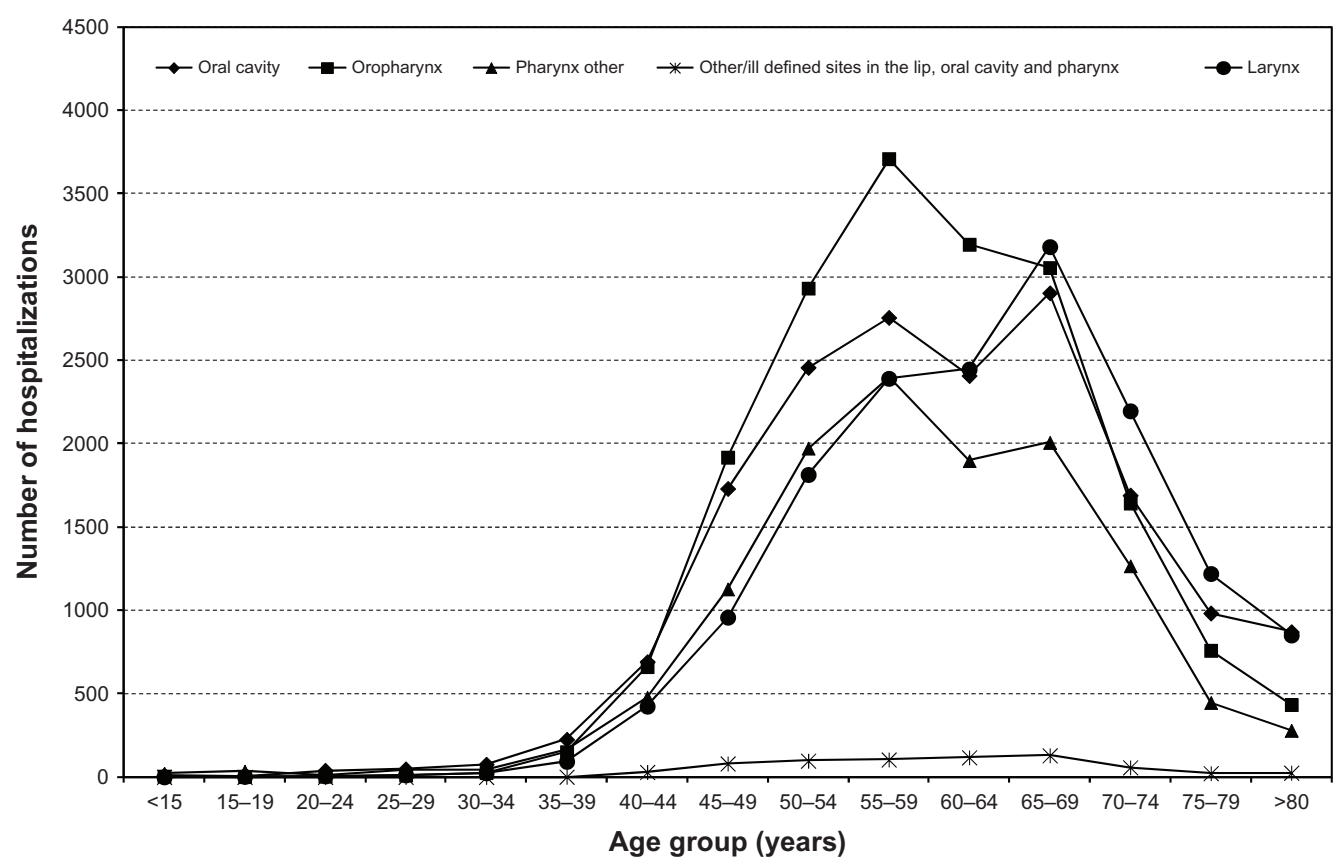

Figure I Age distribution of hospitalizations for head and neck cancers in Germany in 2008.

$€ 3.05$ million to females (23\%). Annual costs for inpatient rehabilitation by cancer category and sex are given in Table 4 . The main contributors to these costs were oropharynx (31\%) and oral cavity cancers $(29 \%)$.

\section{Indirect costs incurred by sick leave}

In 2008, compulsory AOK members comprised $5,409,955$ males and 4,067,300 females. ${ }^{21}$ There were 5224 sick leave cases due to HNCs for males, corresponding to a total of 190,379 sick leave days, and 760 sick leave cases due to HNCs for females, corresponding to a total of 25,477 sick leave days. ${ }^{20}$ In 2008, the total German compulsory SHI member population (insurance members who were working) comprised 15,374,034 males and 14,174,791 females. ${ }^{21}$ Hence, the factors were $15,374,034 / 5,409,955=2.8414$ for males and $14,174,791 / 4,067,300=3.4851$ for females to

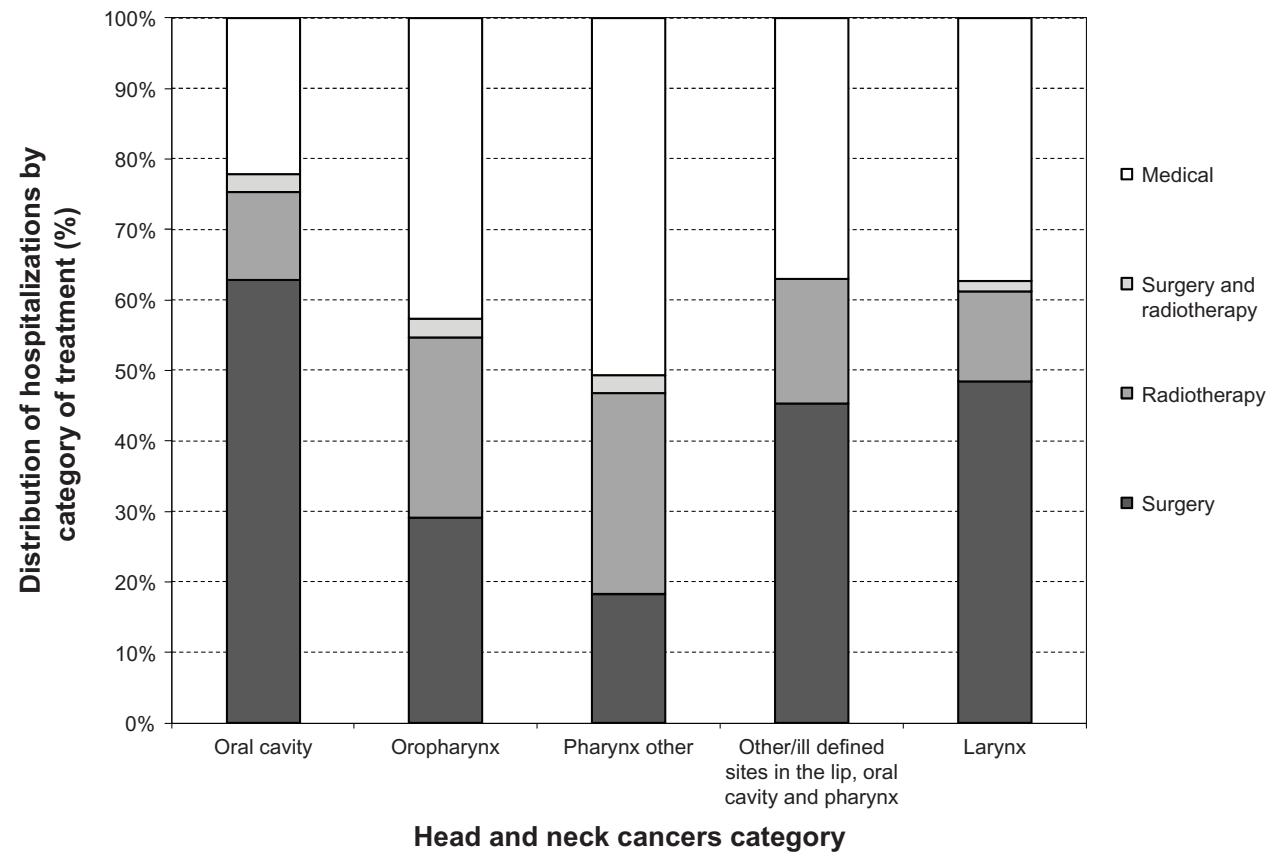

Figure 2 Distribution of hospitalizations by major category of treatment for each head and neck cancer category in Germany in 2008. 
Table 4 Annual costs $(€)$ by head and neck cancer category and sex in Germany in 2008 (any inconsistencies are due to rounding)

\begin{tabular}{|c|c|c|c|c|c|c|}
\hline \multirow{2}{*}{$\begin{array}{l}\text { Cancer category } \\
\text { (ICD-10 code) }\end{array}$} & \multicolumn{2}{|c|}{ Hospitalization } & \multicolumn{2}{|c|}{ Inpatient rehabilitation } & \multicolumn{2}{|l|}{ Sick leave } \\
\hline & Males & Females & Males & Females & Males & Females \\
\hline Oral cavity (C02-C06) & $76,583,404$ & $32,920,298$ & $2,507,822$ & $\mathrm{I}, 257,368$ & $14,876,765$ & $2,873,789$ \\
\hline Oropharynx (COI, C09-CI0) & $61,395,67 \mid$ & $17,587,726$ & $2,992,257$ & $\mathrm{I}, 053,847$ & $14,134,432$ & $2,240,647$ \\
\hline Pharynx other $(\mathrm{CII}-\mathrm{Cl} 3)$ & $38,211,337$ & $6,862,280$ & $|, 849,4| 8$ & 292,735 & $8,474,269$ & $\mathrm{I}, 553,302$ \\
\hline Other sites* $(\mathrm{Cl} 4)$ & $3,482,377$ & 844,411 & 165,939 & 27,880 & 944,159 & $22 I, 06 I$ \\
\hline Larynx (C32) & $49,076,668$ & $6,698,765$ & $2,539,270$ & 417,524 & $12,260,757$ & $1,430,200$ \\
\hline Total & $228,749,457$ & $64,913,480$ & $10,054,708$ & $3,049,355$ & $50,690,382$ & $8,318,999$ \\
\hline
\end{tabular}

Note: *Other/ill-defined sites in the lip, oral cavity, and pharynx.

Abbreviation: ICD-10, International Classification of Diseases, tenth revision ${ }^{6}$.

extrapolate cases and days of sick leave from compulsory AOK members to the total German compulsory member population.

There were 17,494 cases $(85 \%$ for males, $15 \%$ for females) and 629,809 days ( $86 \%$ males, $14 \%$ females) of sick leave due to HNCs in Germany in 2008. The number of sick leaves and the duration in days by cancer category and sex are displayed in Table 3. At a cost of $€ 93.69$ per workday lost, indirect costs incurred by sick leave are estimated at a total of $€ 59.01$ million, with $€ 50.69$ million attributed to males (86\%) and $€ 8.32$ million to females (14\%). The distribution of these costs by cancer category and sex is given in Table 4 . The main contributors to these costs were oral cavity $(30 \%)$ and oropharynx cancers $(28 \%)$.

\section{Annual costs incurred by hospitalization, inpatient rehabilitation, and sick leave}

In 2008, the total annual cost of HNCs amounted to $€ 365.78$ million in Germany, mainly driven by males (79\%).

Of this total cost, $84 \%$ comprised direct costs ( $80 \%$ hospitalization, $4 \%$ inpatient rehabilitation) and $16 \%$ indirect costs incurred by sick leave. The stratification of this total cost by cost category and sex is displayed in Table 5 .

The cancer category-specific prevalence rates of HPV in $\mathrm{HNC}^{2,9}$ (Table 2) applied to the values in Table 4 resulted in the average and range of total annual HPV-related cost

Table 5 Total annual costs ( $€$ million) of head and neck cancers by cost category and sex in Germany in 2008 (any inconsistencies are due to rounding)

\begin{tabular}{llll}
\hline Cost category & Males & Females & Both sexes \\
\hline Direct costs & & & \\
Hospitalization & 228.75 & 64.91 & 293.66 \\
$\begin{array}{l}\text { Inpatient rehabilitation } \\
\text { Subtotal }\end{array}$ & 10.05 & 3.05 & 13.10 \\
$\begin{array}{l}\text { Indirect costs } \\
\text { Sick leave }\end{array}$ & 238.80 & 67.96 & 306.77 \\
Total & 50.69 & 8.32 & \\
\hline
\end{tabular}

of HNCs stratified by cost category and sex (Table 6). The economic burden of HNCs attributable to HPV infection amounted to an average of $€ 78.22$ million ( $80 \%$ males compared with $20 \%$ females) with a range of $€ 66.41$ million to $€ 137.57$ million.

\section{Discussion}

This study estimated that the annual cost due to hospitalization, inpatient rehabilitation, and sick leave incurred by HPVrelated HNCs in Germany in 2008 was $€ 78.22$ million, which was mainly attributed to males ( $80 \%$ ), with $84 \%$ of the total comprised of direct costs $(80 \%$ hospitalization, $4 \%$ inpatient rehabilitation) and $16 \%$ indirect costs due to sick leave.

The present study used a cross-sectional approach to estimate these annual costs. The data used to estimate the number of hospitalizations, ${ }^{17}$ inpatient rehabilitations, ${ }^{19}$ and sick leave ${ }^{20}$ are from patients with at least one such resource consumption in the reference year. Thus, as the numbers refer to resource use or consumption and not to single patients in that year, ${ }^{17-20}$ no patient level information is available with respect to comorbidities or numbers of hospitalizations,

Table 6 Average and range of total annual human papillomavirusrelated costs ( $€$ million) of head and neck cancers by cost category and sex in Germany in 2008 (any inconsistencies are due to rounding)

\begin{tabular}{|c|c|c|c|}
\hline Cost category & Males & Females & Both sexes \\
\hline \multicolumn{4}{|l|}{ Direct costs } \\
\hline Hospitalization & $\begin{array}{l}49.14 \\
(41.14-85.66)\end{array}$ & $\begin{array}{l}13.35 \\
(12.26-24.26)\end{array}$ & $\begin{array}{l}62.49 \\
(53.40-109.92)\end{array}$ \\
\hline $\begin{array}{l}\text { Inpatient } \\
\text { rehabilitation }\end{array}$ & $\begin{array}{l}2.23 \\
(1.8 I-3.92)\end{array}$ & $\begin{array}{l}0.66 \\
(0.59-1.24)\end{array}$ & $\begin{array}{l}2.88 \\
(2.40-5.16)\end{array}$ \\
\hline Subtotal & $\begin{array}{l}51.37 \\
(42.95-89.57)\end{array}$ & $\begin{array}{l}|4.0| \\
(|2.85-25.5|)\end{array}$ & $\begin{array}{l}65.38 \\
(55.8 \mathrm{I}-\mathrm{II} 5.08)\end{array}$ \\
\hline \multicolumn{4}{|l|}{ Indirect costs } \\
\hline Sick leave & $\begin{array}{l}11.05 \\
(9.05-19.33)\end{array}$ & $\begin{array}{l}1.79 \\
(1.56-3.16)\end{array}$ & $\begin{array}{l}12.84 \\
(10.61-22.49)\end{array}$ \\
\hline Total & $\begin{array}{l}62.42 \\
(52.01-108.90)\end{array}$ & $\begin{array}{l}15.80 \\
(14.4 \mid-28.67)\end{array}$ & $\begin{array}{l}78.22 \\
(66.4 \mathrm{I}-137.57)\end{array}$ \\
\hline
\end{tabular}


inpatient rehabilitations or sick leaves, each per patient per year. Additionally, for hospital treatment, no incident cases with high resource consumption can be distinguished from prevalent cases with less resource consumption due to the nature of the databases ${ }^{17,18}$ available. Thus, the estimated average cost of hospitalization due to HNCs of $€ 4599$ (from $€ 3571$ for larynx cancer up to $€ 6546$ for cancer of other sites $)^{18,22,23}$ reflects the average cost of all HNC cases treated in the hospital. It is consequently lower than the average cost per patient or per new case, as patients may be hospitalized several times per year. For example, in The Netherlands, cost was $€ 21,858$ per HNC patient for the first 2 years following diagnosis and decreased to $€ 423$ during the 10 years of follow-up (1996 values). ${ }^{14}$

In Germany in 2008, there were 17,130 incident cases of HNCs (13,130 males and 4000 females). ${ }^{7}$ The 5-year partial prevalence (ie, number of patients alive with a diagnosis of cancer for no longer than 5 years who are likely to receive primary treatment) is the best suited reference point to be compared with the number of treated cases in 2008 found in this study. The 5-year partial prevalence amounted to about 46,900 patients with HNCs in Germany in 2008. ${ }^{7}$ These 5-year partial prevalence data compare well to 63,857 hospitalizations, found in the present study for the year of 2008 in Germany. However, the numbers of cancers of interest to which we applied specific proportions attributable to HPV infection might have been slightly overestimated. Coding systems often limit data accuracy, and some of the ICD-10 codes used in the present study to identify HNCs of interest covered specific locations that have not yet been formally linked to HPV (eg, nasopharynx).

The estimation of costs incurred by sick leave was based on the sex-specific extrapolation of the AOK data ${ }^{20}$ to the total German compulsory SHI member population in $2008 .{ }^{21}$ This extrapolation may have been limited by the fact that the age distribution is not given in the $\mathrm{AOK}$ data ${ }^{20}$ and compulsory AOK members are of somewhat lower socioeconomic status than average. ${ }^{26}$ In 2008, compulsory AOK members had 11.74 days of sick leave per sick leave case and 106.5 sick leave cases per 100 members. ${ }^{27}$ The total German compulsory SHI member population had 12.45 days of sick leave per sick leave case and 95.1 sick leave cases per 100 members. ${ }^{28}$ Therefore, the bias introduced by the extrapolation of the cancer-specific sick leave data of the compulsory AOK members $^{20}$ to the total German compulsory SHI member population $^{21}$ may be minimal. In addition, more than half $(53 \%)$ of the hospitalizations for HNCs were for patients older than 60 years (Figure 1); this is past the average age of retirement of 60.7 years in Germany in $2008 .^{29}$ Hence, the mentioned minimal extrapolation bias only affects a relatively small amount of indirect costs due to sick leave of employed patients with $\mathrm{HNCs}$ - that is, those younger than the average retirement age.

However, as the other half of the hospitalizations for HNCs were for patients younger than 60 years (Figure 1) that is, below the average retirement age in Germany, ${ }^{29}$ the expected increase in HNC incidence, especially in younger age groups, ${ }^{1,7}$ will lead to an increase in indirect costs due to loss of productivity in addition to an increase in direct costs incurred by treatment of patients with HNCs.

Several factors contribute to the strength of the present study. Most importantly, the data sources used for the number of the cancer-specific hospitalizations ${ }^{17}$ and inpatient rehabilitations ${ }^{19}$ were by law exhaustive for all Germany. These databases were also used in previous cost-of-illness (CoI) analyses. ${ }^{30-32}$ In addition, the quality of coding and case allocation of complex head and neck surgery cases within the G-DRG system was improved in 2008 compared with the years before. ${ }^{33}$ Thus, the G-DRG-based costs of hospitalizations incurred by HNCs used in the study presented here are very likely to represent valid cost estimates.

Limitations of this study are mainly linked to the cost components covered compared with the components of overall CoI. This study covered only three out of eleven components of overall CoI (Table 1); it excluded important expenses categories such as outpatient management and patients' co-payments and out-of-pocket expenses, which are likely to be important contributors to the total economic burden of HNC management. In addition to the restrictions already mentioned, costs incurred by complications, side effects, or sequelae of the treatment of HNCs, such as side effects relating to dysphagia or mucositis, usually managed in outpatient care, were not included. Management costs of dysphagia are reported to range between US\$153 and US\$710 34 and between $€ 3480$ and $€ 4764$ per episode of mucositis. ${ }^{13}$ Given these factors, it is clear that this study underestimated the total annual cost of HNCs and of HPV-related HNCs in Germany in 2008 to a considerable extent. However, to avoid speculative assumptions and maintain a conservative approach, no attempts were made to roughly estimate the potential contribution of all the costs not included.

Due to the differences in study designs, national health care systems, unit costs, incidence patterns, and in cost components covered, the results of the present study are difficult to compare with those of other CoI analyses of HPVrelated HNCs. ${ }^{2-4,12-16}$ However, the results of our study are 
similar to results found for France ${ }^{2}$ with respect to hospital costs. Costs incurred by hospitalization for HNCs amounted to $€ 284.43$ million (2007 values), with $€ 73.95$ million attributable to HPV infection in France, ${ }^{2}$ compared with $€ 293.66$ million and $€ 62.49$ million, respectively, in our study in Germany (2008 values).

Costs incurred by HPV-related HNCs are significant in males rather than females $(80 \%$ for males in the present study). There is growing evidence of a causal role for HPV in HNCs. ${ }^{35}$ Over the past decades, the proportion of HPVpositive oral cancers has significantly increased, while, at the same time, HPV-negative cancers have decreased. ${ }^{1,36,37}$ As since 2008 - the reference year for cost estimation in the present study -5 years have passed, the impact of a change in resource consumption and in unit costs (prices) should be discussed. An increase in resource consumption due to an increase in the incidence of HPV-related HNC $\mathrm{HN}^{1,36,37}$ could not be considered as the nature of the databases ${ }^{17,19,20}$ available does not allow incident cases to be distinguished from prevalent cases. The impact of increasing unit costs, however, could be examined using 2011 as the most recent common reference year. ${ }^{38-40}$ The Germany-wide average base rate of $€ 2803.05$ in $2008^{22,23}$ for calculation of direct costs incurred by hospitalization increased to $€ 2963.82$ in $2011,{ }^{38}$ an average annual percentage change (APC) of $1.02 \%$. The average cost of $€ 111.52$ per day for inpatient rehabilitation in $2011^{19}$ increased to $€ 113.20$ in $2011,{ }^{39}$ an APC of $1 \%$. The overall employee compensation per employee per day for calculation of indirect costs incurred by sick leave increased from $€ 93.69$ in $2008^{25}$ to $€ 98.99$ in $2011,{ }^{40}$ an APC of $1.02 \%$. Assuming these APCs were also applicable during 2008 and through to 2013, and a steady resource consumption during 2008 to 2013, leads to an expected economic burden of HPV-related HNCs of an average of $€ 85.60$ million with a range of $€ 72.69$ million to $€ 150.57$ million in 2013 based on extrapolating the values for 2008 given in Table 6 . This is an increase of about $9.5 \%$ from 2008 to 2013 . When also considering the increase in the incidence of HPV-related $\mathrm{HNCs}$, ${ }^{1,36,37}$ the increase in the economic burden of HPV-related HNCs would be even higher over the 5-year period.

HPV vaccination has demonstrated high prophylactic efficacy against pre-cancerous lesions of the cervix, vulva, and vagina. Recently, the quadrivalent HPV vaccine has demonstrated high clinical efficacy on anal pre-cancers in males. ${ }^{41}$ One can speculate that HPV vaccination might extend protection against other cancers associated with HPV 16 and 18. Therefore, data from the present study could be useful for decision-makers who must assess the potential effect of HPV vaccination on the incidence of HNCs in males and females.

\section{Conclusion}

To our knowledge, this study is the first analysis to have investigated the economic burden of HNCs incurred by hospitalization, inpatient rehabilitation, and sick leave in Germany. The estimated annual costs of HPV-related HNCs contribute to a significant economic burden of at least $€ 78.22$ million in Germany; this information could be useful for decisionmakers in terms of assessing whether an HPV vaccination strategy would be cost-effective in Germany, considering the potential vaccine's impact on the burden of HPV-associated HNCs. Further, these costs are underestimated since, inter alia, outpatient management and management of precursor lesions could not be included, as there is currently no data on these. Hence, further research is required to fully estimate the economic burden of HPV-related HNCs in Germany.

\section{Authorship}

All authors contributed equally to conception and design, acquisition, analysis, and interpretation of the data as well as to drafting and critical review of this article. All authors read and approved the final version prior to publication.

\section{Acknowledgments}

The authors are grateful to L Moro, employee of Sanofi Pasteur MSD (SPMSD), Lyon, France, at the time of conduct of the study and writing of the manuscript, and to N Largeron and E Préaud, employees of SPMSD, for their comments on an earlier version of the manuscript.

\section{Disclosure}

This study was funded by an unrestricted grant from SPMSD. JPK has received remunerations from SPMSD. PKS and XC are employees of IGES Institut, Berlin, Germany, and have worked on projects of IGES Institut that have been funded by SPMSD. VR is an employee of SPMSD, manufacturer of one HPV vaccine.

This study was presented at the 27th International Papillomavirus Conference, Berlin, Germany, September 17-22, 2011 and at the 14th Annual European Congress of the International Society for Pharmacoeconomics and Outcomes Research, Madrid, Spain, November 5-8, 2011.

\section{References}

1. Blomberg M, Nielsen A, Munk C, Kjaer SK. Trends in head and neck cancer incidence in Denmark, 1978-2007: focus on human papillomavirus associated sites. Int J Cancer. 2011;129(3):733-741. 
2. St Guily JL, Borget I, Vainchtock A, Rémy V, Takizawa C. Head and neck cancers in France: an analysis of the hospital medical information system (PMSI) database. Head Neck Oncol. 2010;2:22.

3. Menzin J, Lines LM, Manning LN. The economics of squamous cell carcinoma of the head and neck. Curr Opin Otolaryngol Head Neck Surg. 2007;15(2):68-73.

4. Parkin DM, Bray F. Chapter 2: The burden of HPV-related cancers. Vaccine. 2006;24 Suppl 3:S3/11-25.

5. Ferlay J, Shin HR, Bray F, Forman D, Mathers C, Parkin DM. GLOBOCAN 2008 v 1.2, cancer incidence and mortalityworldwide in 2008: IARC CancerBase No 10 [web page on the Internet]. Lyon: International Agency for Research on Cancer; 2010. Available from: http://globocan. iarc.fr. Accessed April 27, 2012.

6. World Health Organization (WHO). International Classification of Diseases. 10th revision. Geneva: WHO; 1990.

7. Robert Koch Institute, Society of Cancer Registries in Germany. Krebs in Deutschland 2007/2008 [Cancer in Germany 2007/2008]. Berlin: Robert Koch Institute, Society of Cancer Registries in Germany; 2012. German.

8. Klussmann JP, Weissenborn SJ, Wieland U, et al. Prevalence, distribution, and viral load of human papillomavirus 16 DNA in tonsillar carcinomas. Cancer. 2001;92(11):2875-2884.

9. Kreimer AR, Clifford GM, Boyle P, Franceschi S. Human papillomavirus types in head and neck squamous cell carcinomas worldwide: a systematic review. Cancer Epidemiol Biomarkers Prev. 2005;14(2): $467-475$.

10. Guntinas-Lichius O, Wendt T, Buentzel J, et al; Thuringian Head and Neck Cancer Study Group. Head and neck in situ carcinoma: survival analysis of the Thuringian cancer registration database. Oral Oncol. 2010;46(4):e5-e9.

11. Guntinas-Lichius O, Wendt T, Buentzel J, et al. Head and neck cancer in Germany: a site-specific analysis of survival of the Thuringian cancer registration database. J Cancer Res Clin Oncol. 2010;136(1): $55-63$.

12. Lee JM, Turini M, Botteman MF, Stephens JM, Pashos CL. Economic burden of head and neck cancer. A literature review. Eur J Health Econ. 2004;5(1):70-80.

13. Peterman A, Cella D, Glandon G, Dobrez D, Yount S. Mucositis in head and neck cancer: economic and quality-of-life outcomes. J Natl Cancer Inst Monogr. 2001;(29):45-51.

14. van Agthoven M, van Ineveld BM, de Boer MF, et al. The costs of head and neck oncology: primary tumours, recurrent tumours and long-term follow-up. Eur J Cancer. 2001;37(17):2204-2211.

15. Ekwueme DU, Chesson HW, Zhang KB, Balamurugan A. Years of potential life lost and productivity costs because of cancer mortality and for specific cancer sites where human papillomavirus may be a risk factor for carcinogenesis-United States, 2003. Cancer. 2008;113(Suppl 10):2936-2945.

16. Hu D, Goldie SJ. The economic burden of noncervical human papillomavirus disease in the United States. Am J Obstet Gynecol. 2008;198(5): 500. e1-e7.

17. Federal Statistical Office Germany. Tiefgegliederte Diagnosedaten der Krankenhauspatientinnen und -patienten 2008 [Deeply structured diagnostic data of hospital patients 2008]. Federal Statistical Office Germany. Wiesbaden, Germany. 2009. Available from: https://www-ec. destatis.de. Accessed January 4, 2011. German.

18. Institute for the Hospital Remuneration System in Germany. GDRGBrowser_2008_Par21_100202.zip (G-DRG V2009 Daten 2008 gem. $\S 21$ KHEntgG - G-DRG Browser) 2010. Editor Institute for the Hospital Remuneration System in Germany. Siegburg, Germany. 2010. Available from: http://www-g-drg.de. Accessed March 15, 2010. German.

19. German Public Pension Insurance. Statistik der Deutschen Rentenversicherung. Band 174. Rehabilitation 2008 [Statistics of the German Public Pension Insurance. Volume 174. Rehabilitation 2008]. Berlin: German Public Pension Insurance; 2009. German.
20. Federal Health Monitoring Germany. Arbeitsunfähigkeit bei AOKMitgliedern ohne Rentner. Jahr 2008: Arbeitsunfähigkeitsfälle, Arbeitsunfähigkeitstage, Tage je Fall (Gliederungsmerkmale: Jahre, Deutschland, Geschlecht, ICD-10) [Inability to work of compulsory members of the Local Statutory Health Insurance (AOK) without pensioners (cases and days of inability to work, days of inability to work per 100,000 compulsory members, days per case). Classification: years, Germany, sex, ICD-10]. Federal Health Monitoring Germany; 2008. Editor Federal Statistical Office Germany, Branch Bonn. Bonn, Germany. 2010. Available from: http://www.gbe-bund.de/oowa921-install/servlet/oowa/aw92/ dboowasys921.xwdevkit/xwd_init?gbe.isgbetol/xs_start_neu/\&p_ aid=3\&p_aid=91546134\&nummer=683\&p_sprache=D\&p_indsp=\&p_aid=70513394. Accessed December 7, 2010. German.

21. German Federal Ministry of Health. Mitgliederstatistik KM6 2008 [Membership statistics KM6 2008]. German Federal Ministry of Health; 2008. Bonn. Available from: http://www.bmg.bund.de/fileadmin/redaktion/excel_statistiken/krankenversicherung/KM6-juli-08.xls. Accessed January 11, 2011. German.

22. Platzer H. Zukünftige Vergütungsstrukturen der Krankenhäuser [Future remuneration structures of hospitals]. Munich: AOK Bavaria; 2008. Available from: http://www.oberender-online.de/fileadmin/oberender/ pdf/Platzer_ExpertentagungUniBayreuth_08052008.pdf. Accessed December 12, 2010. German.

23. von der Schulenburg JM, Prenzler A, Schurer W. Cancer management and reimbursement aspects in Germany: an overview demonstrated by the case of colorectal cancer. Eur J Health Econ. 2010;10 Suppl 1: S21-S26.

24. Graf von der Schulenburg JM, Greiner W, Jost F, et al; Hanover Consensus Group. German recommendations on health economic evaluation: third and updated version of the Hanover Consensus. Value Health. 2008;11(4):539-544.

25. Federal Statistical Office Germany. Statistical Yearbook 2010 for the Federal Republic of Germany including International Tables. Wiesbaden: Federal Statistical Office Germany; 2010. German.

26. Schnee M. Sozioökonomische Strukturen und Morbidität in den gesetzlichen Krankenkassen [Socioeconomic structures and morbidity in the Statutory Health Insurance funds]. In: Böcken J, Braun B, Amhof R, editors. Gesundheitsmonitor 2008 [Health monitor 2008]. Gütersloh: Verlag Bertelsmann Stiftung; 2008:88-104. German.

27. Federal Health Monitoring Germany. Arbeitsunfähigkeit bei AOKMitgliedern ohne Rentner. Jahr 2008: Arbeitsunfähigkeitstage, Arbeitsunfähigkeitsfälle, Tage je Fall (Gliederungsmerkmale: Jahre, Kassenart, Versichertengruppe) [Disability at AOK members excluding pensioners. 2008: lost work days, disability cases, days per case (Classification: years, statutory health insurance group)]. Federal Health Monitoring Germany; 2008. Editor Federal Statistical Office Germany, Branch Bonn. Bonn, Germany. 2010. Available from: http://www.gbe-bund. de. Accessed January 22, 2011. German.

28. Federal Health Monitoring Germany. Arbeitsunfähigkeit bei Mitgliedern der gesetzlichen Krankenkassen insgesamt ohne Rentner. Jahr 2008: Arbeitsunfähigkeitstage, Arbeitsunfähigkeitsfälle, Tage je Fall (Gliederungsmerkmale: Jahre, Kassenart, Versichertengruppe) [Inability to work: days and cases of inability to work of the members of the Statutory Health Insurance (number and rate). Classification: years, sex, type of statutory health insurance organization, group of people insured]. Federal Health Monitoring Germany; 2008. Editor Federal Statistical Office Germany, Branch Bonn. Bonn, Germany. 2010. Available from: http://www.gbe-bund.de/oowa921-install/servlet/oowa/aw92/ dboowasys921.xwdevkit/xwd_init?gbe.isgbetol/xs_start_neu/\&p_ aid=i\&p_aid=60283303\&nummer=267\&p_sprache=D\&p_indsp=\&p_aid=86537257. Accessed January 22, 2011. German.

29. German Public Pension Insurance. Statistik der Deutschen Rentenversicherung. Band 173. Rentenzugang 2008 [Statistics of the German Public Pension Insurance. Volume 173. Retirement 2008]. Berlin: German Public Pension Insurance; 2009. German. 
30. Brecht JG, Poldrugo F, Schädlich PK. Alcoholism. The cost of illness in the Federal Republic of Germany. Pharmacoeconomics. 1996;10(5): 484-493.

31. Brecht JG, Schädlich PK. Burden of illness imposed by osteoporosis in Germany. Eur J Health Econ. 2000;1(1):26-32.

32. Schädlich PK, Brecht JG. Burden of illness imposed by venous thromboembolism as an original disease in Germany. Perfusion. 2003;16: 250-256.

33. Franz D, Roeder N, Hörmann K, Alberty J. ENT medicine and head and neck surgery in the G-DRG system 2008. HNO. 2008;56(9):874-880. German.

34. Sculpher MJ, Sargeant IR, Loizou LA, Thorpe SM, Spencer GM, Bown SG. A cost analysis of Nd:YAG laser ablation versus endoscopic intubation for the palliation of malignant dysphagia. Eur J Cancer. 1995;31A(10):1640-1646.

35. Goon PK, Stanley MA, Ebmeyer J, et al. HPV and head and neck cancer: a descriptive update. Head Neck Oncol. 2009;1:36.

36. Näsman A, Attner P, Hammarstedt L, et al. Incidence of human papillomavirus (HPV) positive tonsillar carcinoma in Stockholm, Sweden: an epidemic of viral-induced carcinoma? Int J Cancer. 2009;125(2): $362-366$.
37. Chaturvedi AK, Engels EA, Anderson WF, Gillison ML. Incidence trends for human papillomavirus-related and -unrelated oral squamous cell carcinomas in the United States. J Clin Oncol. 2008;26(4): 612-619.

38. AOK-Health Partner. Germany-wide average base rate in 2011. Editor AOK-Bundesverband, Berlin. Available from: http://www.aokgesundheitspartner.de/bund/krankenhaus/lbfw/bfw/index_09446.html. Accessed March 6, 2013. German.

39. German Public Pension Insurance. Statistik der Deutschen Rentenversicherung. Band 189. Rehabilitation 2011 [Statistics of the German Public Pension Insurance. Volume 189. Rehabilitation 2011]. Berlin: German Public Pension Insurance; 2012. German.

40. Federal Statistical Office Germany. Statistical Yearbook Germany and International 2012. Wiesbaden: Federal Statistical Office Germany; 2012. German.

41. Giuliano AR, Palefsky JM, Goldstone S, et al. Efficacy of quadrivalent HPV vaccine against HPV Infection and disease in males. $N$ Engl $J$ Med. 2011;364(5):401-411.
ClinicoEconomics and Outcomes Research

\section{Publish your work in this journal}

ClinicoEconomics \& Outcomes Research is an international, peerreviewed open-access journal focusing on Health Technology Assessment, Pharmacoeconomics and Outcomes Research in the areas of diagnosis, medical devices, and clinical, surgical and pharmacological intervention. The economic impact of health policy and health systems

Submit your manuscript here: http://www.dovepress.com/clinicoeconomics-and-outcomes-research-journal

\section{Dovepress}

organization also constitute important areas of coverage. The manuscript management system is completely online and includes a very quick and fair peer-review system, which is all easy to use. Visit http://www.dovepress.com/testimonials.php to read real quotes from published authors. 